\title{
Proceeding
}

Supplementary Issue: Summer Conferences of Sports Science. Costa Blanca Sports Science Events, 25-26 September 2020. Alicante, Spain.

\section{Parental influence on children's cardiometabolic risk factors and cardiorespiratory fitness}

\author{
ANDREA CASOLO ${ }^{1,2}$, STEFANO NUCCIO ${ }^{3}$, ESTER TOMMASINI ${ }^{1}$, FRANCESCO CASOLO ${ }^{4}$, CHRISTEL \\ GALVANI ${ }^{5}$ \\ ${ }^{1}$ Catholic University of Sacred Heart, Milan, Italy \\ ${ }^{2}$ Department of Bioengineering, Imperial College London, London, United Kingdom \\ ${ }^{3}$ Department of Movement, Human and Health Sciences, University of Rome "Foro Italico", Rome, Italy \\ ${ }^{4}$ Department of Pedagogy, Catholic University of Sacred Heart, Milan, Italy \\ ${ }^{5}$ Applied Exercise Physiology Laboratory, Department of Psychology, Catholic University of Sacred Heart, Milan, Italy
}

\begin{abstract}
The parental influence on children's cardiometabolic risk factors (CMRF) and cardiorespiratory fitness (CRF) has been only marginally investigated. Hence, this study aimed to investigate whether parental CMRF and CRF were associated with those of their school-aged children. This cross-sectional analysis included 53 Italian school-children along with their parents. CMRF were assessed by measuring the waist circumference (WC) and by computing the waist-to-height ratio (WHtR), whereas CRF was estimated with the six-minute walking test (6MWT). A multiple stepwise backward elimination regression analysis was performed to investigate associations between parental and children's features. Both parental WC and WHtR were associated with children's ones $\left(R^{2}=0.28, p=.005 ; R^{2}=0.18, p=.041\right)$. Maternal WC and WHtR strongly predicted primary-school children's CMRF $\left(R^{2}=0.54, p=.005 ; R^{2}=0.67, p=.001\right)$. No significant parental influence was observed for CRF. This study investigated, for the first time, the associations between parental CMRF and CRF, and those of their children. Our results suggest that children's WC and WHtR, but not CRF, can be predicted by their parent's parameters. Maternal CMRF may have a stronger influence on children's ones, compared to fathers, particularly during primary-school years.

Keywords: Health-related risk factors; Physical fitness; Parental influence; School-children; Waist-to-height ratio (WHtR); Six-minute walking test (6MWT).

Cite this article as:

Casolo, A., Nuccio, S., Tommasini, E., Casolo, F., \& Galvani, C. (2020). Parental influence on children's cardiometabolic risk factors and cardiorespiratory fitness. Journal of Human Sport and Exercise, 15(4proc), S1354-S1366. doi:https://doi.org/10.14198/jhse.2020.15.Proc4.33

Corresponding author. Applied Exercise Physiology Laboratory, Department of Psychology, Catholic University of Sacred Heart, Milan, Italy. https://orcid.org/0000-0002-0126-6033

E-mail: christel.galvani@unicatt.it

Abstract submitted to: Spring Conferences of Sports Science. Costa Blanca Sports Science Events, 19-20 June 2020. Alicante, Spain.

JOURNAL OF HUMAN SPORT \& EXERCISE ISSN 1988-5202

(c) Faculty of Education. University of Alicante

doi:10.14198/jhse.2020.15.Proc4.33
\end{abstract}

S1354 | 2020| Proc4 | VOLUME 15

C 2020 University of Alicante 


\section{INTRODUCTION}

It has been suggested that anthropometric features, such us body mass index (BMI) and waist circumference (WC), are associated with mortality risk (Koster et al., 2008). However, a growing body of evidence in support of the higher predictability of waist-to-height ratio (WHtR) over WC and BMI of cardiometabolic outcomes in adults (Ashwell et al., 2012), as well as in younger populations (Ashwell, 2009), has recently emerged. In particular, a recent metanalysis pointed out that WHtR represents a time-convenient and effective indicator of cardiometabolic risk factors (CMRF) in children at any early age (Lo et al., 2016). In addition, a higher level of cardiorespiratory fitness (CRF), a health-related component of physical fitness, has been associated with both a decreased all-cause mortality in women (Farrell et al., 2002) and a reduced heart failure mortality risk in men (Farrell et al., 2013). Similarly, children and adolescents with higher CRF have a lower risk of clustering of cardiovascular disease risk factors, independently of country, age and sex, with respect of those with lower CRF, who may show higher blood pressure, dyslipidaemia and insulin resistance (Anderssen et al., 2007). Moreover, moderate to high levels of CRF are associated with lower abdominal adiposity in children (Ortega et al., 2007) and with both total adiposity and abdominal fat in adults (Janssen et al., 2004). Interestingly, higher levels of CRF have also been associated with a substantial reduction of metabolic risks, regardless of adiposity levels, across the lifespan (Lee et al., 2005; Parrett et al., 2011).

In light of the unprecedented worldwide increase of the prevalence of overweight and obesity among children (Wang and Lobstein, 2006), the understanding of the main factors that may influence children's CMRF and CRF has become a public health priority. In this regard, an important role seems to be played by children's parents. Specifically, existing evidence suggests that parental BMI is moderately correlated with the BMI of their children (Börnhorst et al., 2020; Farajian et al., 2014; Han et al., 2015; Jago et al., 2004; Jelastopulu et al., 2012) and/or with their fatness, evaluated through skinfold thickness (Magnússon et al., 2008). Conversely, there is currently only limited evidence of parental WC and WHtR influence on those of their children. Moreover, it is still unclear if the association between parental and children's CMRF may differ across the different stages of education (i.e. primary-, middle- and high-school). For instance, a recent study reported a stronger association between parental BMI and middle-school children's BMI (11-12 yr.), compared to preschool (2-4 yr.) and primary-school (5-10 yr.) children (Lee et al., 2019).

Moreover, it has been reported that maternal and paternal current sport participation (Schoeppe et al., 2016) and/or previous physical activity (PA) practice (Christofaro et al., 2018) are positively associated with children's leisure time PA. Another study observed that parental exercise, reported by their children through questionnaires, was positively associated with children's extracurricular sport participation (Cleland et al., 2005). To date, there are only few and indirect evidences regarding the association between parental CRF and that of their offspring (Cleland et al., 2005; Magnússon et al., 2008). For instance, one study suggested that parental exercise participation may have a positive effect on children's CRF, assessed through the 1.6 $\mathrm{km}$ run/walk test (Cleland et al., 2005). In another cross-sectional study it was reported that if on one side, the mothers may have a stronger influence on children's weight/fatness than fathers, on the other, the fathers may have a stronger influence on children's fitness, evaluated with a maximal cycle ergometer test (Magnússon et al., 2008). However, a common methodological approach to all previous studies, which sought to demonstrate the association between parental and children's CRF, is that CRF has been directly assessed only in children while parents' CRF has been inferred mainly by adopting subjective evaluations (e.g. questionnaires). Indeed, to the best of our knowledge, no previous study has investigated the association between parental and children's CRF through the adoption of the same objective field test. 
Accordingly, the aim of this study was to investigate the parental influence on CMRF and CRF levels of school-aged children (6-19 yr.), both evaluated through objective assessments, such as WC, WHtR and the six-minute walking test (6MWT). Secondary aims were to identify if parental influence may differ across the different stages of education (i.e., primary- vs. middle- vs high-school), as well as a possible differential role played by mothers and fathers.

\section{METHODS}

\section{Participants}

This cross-sectional survey included children and youth (age, 6-19 yr.), along with their parents (age, 38-64 yr.), recruited from two scholastic institutions from the Province of Varese, Lombardy, Italy. The exclusion criteria were as follows: known or underlying cardiac, respiratory, neurological or musculoskeletal disorders, or conditions or medications that could interfere with performance physical tests (e.g. 6MWT), or documented inability to participate to physical education classes. In particular, fifty-three boys and girls (32.1\% females) attending primary- (age, 6-11 yr.), middle- (age, 11-14 yr.) and high- (age, 14-19 yr.) school classes and seventy-three parents (mothers, $n=40$; fathers, $n=33$ ), for a total of forty-five families, were enrolled in the study. Participant's anthropometric characteristic are presented in Table 1.

Written informed consent from parents, or legal guardians, as well as children verbal consent were obtained prior to data collection. The study procedures and protocols were approved by the institutional scientific committee (Università Cattolica del Sacro Cuore, Milan, Italy) and by the institutional boards of the involved schools and conformed to the standards set by the Declaration of Helsinki.

Table 1. Participants' anthropometric characteristics, grouped by school level (primary-, middle-, high-school) and parental role (mother, father). Data are means \pm SD.

\begin{tabular}{lcccc}
\hline & $\mathbf{n}$ & Age $(\mathbf{y r})$. & Body height $(\mathbf{m})$ & Body mass $(\mathbf{k g})$ \\
\hline School level & & & & \\
Primary & 14 & $7.7 \pm 1.5$ & $1.30 \pm 0.09$ & $29.8 \pm 7.9$ \\
Middle & 16 & $12.3 \pm 1.0$ & $1.60 \pm 0.13$ & $48.8 \pm 11.8$ \\
High & 23 & $15.7 \pm 1.9$ & $1.70 \pm 0.09$ & $61.2 \pm 12.5$ \\
Total & 53 & $12.5 \pm 3.6$ & $1.56 \pm .019$ & $49.2 \pm 16.9$ \\
Parents & & & & \\
Mother & 33 & $45.6 \pm 3.7$ & $1.63 \pm 0.06$ & $61.1 \pm 9.7$ \\
Father & 40 & $47.0 \pm 5.8$ & $1.77 \pm 0.07$ & $80.1 \pm 12.9$ \\
Total & 73 & $46.2 \pm 4.8$ & $1.69 \pm 0.10$ & $69.7 \pm 14.7$ \\
\hline
\end{tabular}

\section{Study design}

This research project was developed during a regular school year (September-May) and involved two main phases. Phase 1 (September-December) was dedicated to the presentation of the purpose, experimental procedures and protocols to the involved families. Phase 2 (January-May) included the assessment of participants' anthropometric characteristics, cardiometabolic risk factors (CMRF), and cardiorespiratory fitness. Children's and youth's data gathering was performed at the beginning of curricular physical education hours, whereas parental data were collected by appointment every week according to their availabilities. All tests and assessments involved the adoption of standardized techniques and procedures and were led by the same experienced investigators. 


\section{Experimental procedures}

Anthropometric assessment

Body height and body mass were measured according to standard procedures, with participants being in upright position, with bare feet placed slightly apart, arms extended along the sides, head parallel to the floor and only wearing light clothing. Body mass was measured to the nearest $\pm 0.1 \mathrm{~kg}$ with a calibrated mechanical scale (SECA 761, Hamburg, Germany). Standing body height was measured to the nearest $\pm 1 \mathrm{~mm}$ with a portable stadiometer (SECA 213, Hamburg, Germany).

Subsequently, body mass index (BMI) was calculated by dividing body mass by height squared $\left(\mathrm{kg} \cdot \mathrm{m}^{-2}\right)$. Based on their BMl, age and gender, participants were classified as underweight, normal weight, overweight or obese according to the relative specific cut-offs (Cole, 2000; Cole et al., 2007; World Health Organization, 2000).

Cardiometabolic risk factors assessment

Waist circumference (WC), which is considered a good proxy for central adiposity, was measured with a retractable measuring tape (SECA 201, Hamburg, Germany) with the subject in a standing position. Measurements were taken by placing the tape horizontally around the waist (parallel to the floor) between the 10th rib lower margin and the upper margin of the anterior iliac crest (McCarthy et al., 2001a\&b). The average value of two consecutive measurements was recorded. Based on their WC, age and gender, children and youth were classified as above the average ( $>50^{\text {th }}$ percentile), within the average (50th percentile) or below the average ( $<50^{\text {th }}$ percentile) (McCarthy et al., 2001a). Similarly, the parents were classified as a "very low", "low", "high" or "very high" risk for health (Bray, 2004).

Waist-to-height ratio (WHtR) was calculated as waist circumference divided by height. Available reference cut-off points for WHtR were adopted to classify participants into four health risk categories: 1) "take care"; 2) "ok"; 3) "consider action" or 4) "take action" (Ashwell, 2009).

\section{Cardiorespiratory fitness assessment}

Approximately after 10 minutes from anthropometric assessment, participants' CRF was evaluated through the 6MWT, which is a feasible, reliable and valid functional test, for assessing exercise tolerance and endurance in healthy children and adolescents (Casolo et al., 2019; Li, 2005; Vandoni et al., 2018) as well as in adults (Chetta et al., 2006). The test was conducted according to a standardised protocol (American Thoracic Society, 2002). Participants were instructed to walk as fast as possible (self-selected pace) back and forth along a 30-m long walking course, marked on the ground every $3 \mathrm{~m}$, and with cones placed at each end of the course. They were asked to cover as much ground as possible, without running or jogging, over a 6-min period. All the participants received the same instructions before the start and were encouraged by a trained investigator with standardised phrases every $30 \mathrm{~s}$ during the walk. A familiarisation trial (one track walk) was completed prior the beginning of the main test. The participants were told to avoid strenuous physical exercise within $48 \mathrm{~h}$ from the beginning of the test. The participants' 6MWT performance (maximum walked distance covered in $6 \mathrm{~min}$ ) was compared with available reference values for healthy children/adolescents (Geiger et al., 2007) and adults (Chetta et al., 2006).

During the test, participants were equipped with a silicone face mask (7350 series, Hans Rudolph Inc., USA) with head cap, which was connected to a portable hand-held spirometer (Spiropalm 6MWT, Cosmed, Rome, Italy). Minute ventilation (V'E) was measured continuously throughout the 6MWT, to monitor the physiological effort (Qin et al., 2010; Unnithan et al., 1995). The equipment was calibrated according to manufacturer's description prior to measurement. Furthermore, participant's rate of perceived exertion (RPE) was evaluated 
with Borg CR10 scale immediately after the completion of 6MWT (Borg, 1982). In particular, participants were instructed to point out their perceived exertion on the RPE scale, according to established recommendations.

\section{Statistical analysis}

The Shapiro-Wilk test was adopted to assess the normality of distribution of the data, before between-group comparisons. The majority of the dependent variables analysed exhibited a normal distribution. When this condition was satisfied, between-group (parents: mothers vs. fathers; children and youth: primary- vs. middlevs. high-school) differences in anthropometric characteristics (i.e. age, body height and mass, BMI), CMRF (i.e. WC and WHtR), and CRF (i.e. 6MWT distance) were investigated with one-way analyses of variance (ANOVAs). A proper post hoc test was used if necessary (Bonferroni test). Corresponding non-parametric tests were adopted when data were not normally distributed.

Distinct stepwise (backward) regression analyses were performed to assess the influence of parental CMRF and CRF on those of their offspring (i.e. primary-, middle- and high-school). For clarity, in the adopted models, the two independent variables (predictors) were the CMRF of the mother (or CRF) and the CMRF of the father (or CRF), whereas the dependent variable was children's CMRF (or CRF). To examine the individual paternal or maternal contribution, the backward selection model started with both mothers' and fathers' candidate variables in the model. At each step, the least significant variable was removed.

Statistical analyses were performed with StatView Software (version 5.0.1) and data are presented as mean \pm standard deviation (SD). The significance level was set at $p<.05$ for all tests.

\section{RESULTS}

\section{Parental anthropometric characteristics and cardiometabolic risk profile}

According to BMI reference cut-offs for adults, the $63 \%$ of parents was normal weight, $25 \%$ was overweight, $8 \%$ was obese and $4 \%$ was underweight.

Moreover, based on WC cut-off values for adults, the $64 \%$ of parents was at "low-risk" for health, the $21 \%$ was at "high-risk", and the remaining $15 \%$ had a "very low-risk". When compared to reference WHtR cut-off values, the $47 \%$ of parents was classified as "ok", the $40 \%$ as "consider action", the $8 \%$ as "take action" and the remaining $5 \%$ as "take care".

Between-group comparisons pointed out that the BMI $\left(23.0 \pm 3.7 \mathrm{vs.} 25.5 \pm 3.6 \mathrm{~kg} \cdot \mathrm{m}^{-2} ; p=.002\right)$ and WC $(0.78 \pm 0.10$ vs. $0.89 \pm 0.11 \mathrm{~m} ; p<.001)$ were significantly lower in children's mothers compared to the fathers (Figure $1 A-B)$. Conversely, no differences were observed for WHtR between mothers and fathers ( $p$ $=.082$, Figure $1 \mathrm{C})$.

\section{Anthropometric characteristics and cardiometabolic risk profile of children and youth}

The comparison with BMl reference cut-offs for children and youth pointed out that the $57 \%$ of primary-school children involved was normal weight, the $36 \%$ was overweight, and the remaining $7 \%$ was underweight. Similarly, the $75 \%$ of middle-school children was normal weight, the $19 \%$ was overweight and the remaining $6 \%$ was underweight. The majority of high-school participants was normal weight $(83 \%)$, the $13 \%$ was overweight, and the $4 \%$ was underweight. Interestingly, none of the children or adolescent involved was classified as obese. 
When compared to reference cut-off points, the $57 \%$ of primary-school children showed a WC above the average, the $29 \%$ within the average, and the $14 \%$ below the average. Similarly, the $56 \%$ of middle-school children had a WC above the average, the $38 \%$ within the average, and the $6 \%$ below the average. More worryingly was the situation observed in high-school adolescents, where about the $70 \%$ was classified with a WC above the average and only the $30 \%$ with a WC within the average. When WHtR cut-off points were applied, the $86 \%$ of primary-school children was classified as "ok", and the remaining $14 \%$ as "take action". Similarly, the majority of middle-school children was classified as "ok", whereas the $25 \%$ as "take care", and the $6 \%$ as "take action". A similar trend was also observed among high-school students, where the $78 \%$ was classified as "ok", the $18 \%$ as "take care", and the $4 \%$ as "take action".

Between-group comparisons pointed out that the BMI was significantly lower in primary- compared to highschool children (17.3 $\left.\pm 2.5 \mathrm{vs} .21 .2 \pm 2.6 \mathrm{~kg} \cdot \mathrm{m}^{-2} ; \mathrm{p}<.001\right)$, and in middle- compared to high-school students $\left(19.0 \pm 2.6 \mathrm{~kg} \cdot \mathrm{m}^{-2} ; p=.004\right)$ (Figure $\left.1 \mathrm{D}\right)$. WC was significantly lower in primary- compared to middle- $(0.59$ \pm 0.07 vs. $0.68 \pm 0.07 \mathrm{~m} ; p=.012)$ and high-school students $(0.73 \pm 0.08 \mathrm{~m} ; p<.001)$ (Figure $1 \mathrm{E})$. WHtR did not differ between the three school age-groups $(p>.05$ in all cases; Figure $1 \mathrm{~F})$.
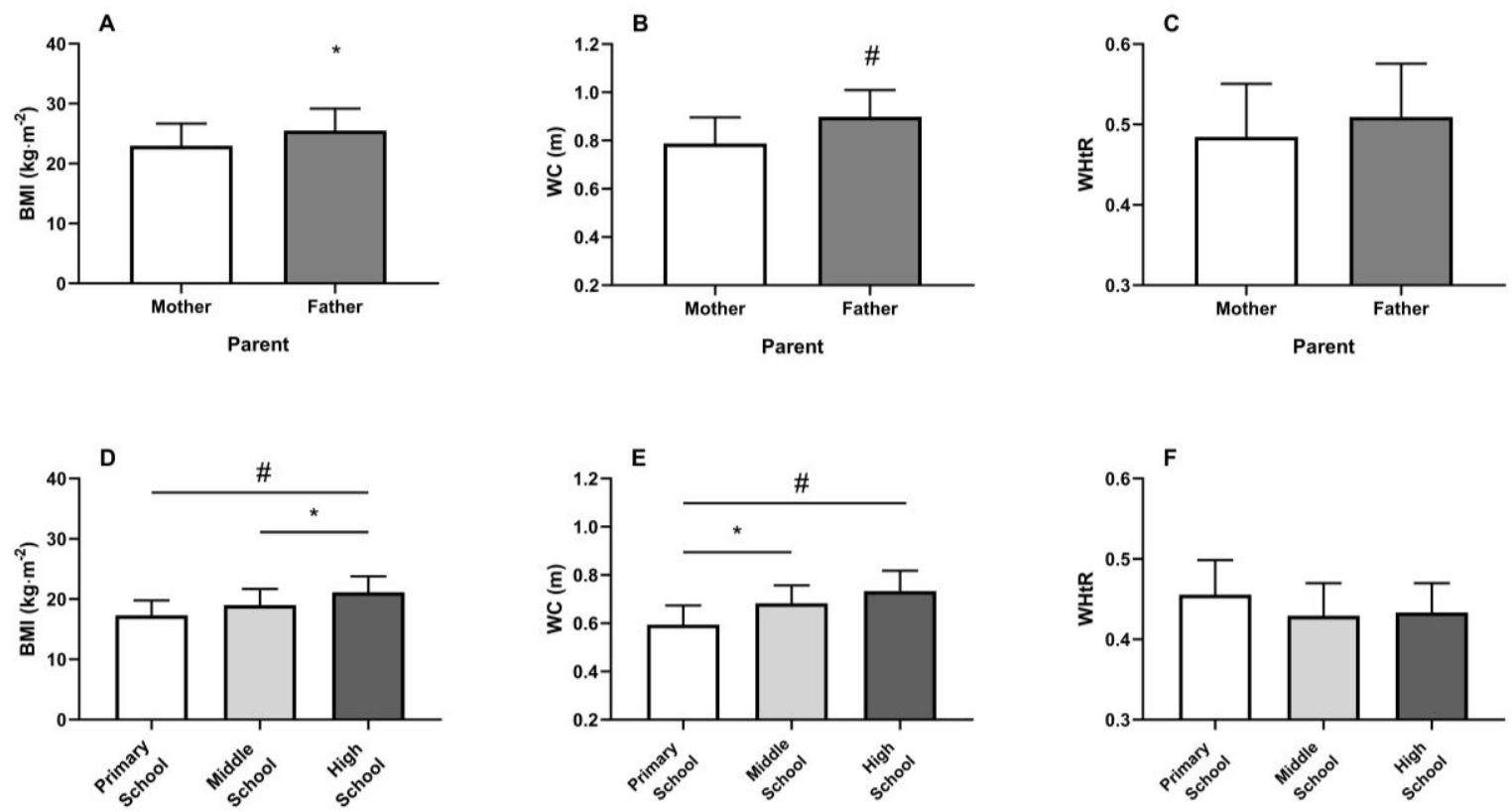

Figure 1. A-B-C. Bar plots representing the average values for BMI $\left(\mathrm{kg} \cdot \mathrm{m}^{-2}\right), \mathrm{WC}(\mathrm{m})$ and $\mathrm{WHtR}$ for mothers (white bars) and fathers (grey bars). D-E-F. Bar plots representing the average values for BMI $\left(\mathrm{kg} \cdot \mathrm{m}^{-2}\right), \mathrm{WC}$ (m) and WHtR for primary- (white bars), middle- (light grey bars) and high-school (dark grey bars) children. Between-group differences are indicated with * if $p<.05$ or with \# if $p<.001$.

\section{Parental cardiorespiratory fitness}

The $61 \%$ of parents presented a 6MWT performance within the average, the $35 \%$ above the average, and the $3 \%$ below the average reference values for adults. The fathers performed a significantly higher 6MWT distance, compared to the mothers $(678.9 \pm 68.1$ vs. $623.5 \pm 43.3 \mathrm{~m} ; p<.001$; Figure $2 \mathrm{~A})$.

The average V'E during 6MWT was $35.9 \pm 8.2$ and $48.9 \pm 15.6 \mathrm{~L} \cdot \mathrm{min}^{-1}$ in mothers and fathers $(p<.001)$, respectively. These values correspond to an overall moderate exercise intensity achieved during the 6MWT. 
Moreover, post-test RPE was $3.4 \pm 2.2$ and $3.3 \pm 2.1$ in mothers and fathers ( $p=.808)$, respectively. These values confirm that both the mothers and fathers perceived intensity of the 6MWT was moderate.

\section{Cardiorespiratory fitness of children and youth}

The $79 \%$ of primary-school children performed the 6MWT within the average, the $14 \%$ below the average, and the $7 \%$ above the average reference values for children and adolescents. Similarly, the majority of middle-school children (56\%) performed within the average, the $25 \%$ below the average and the $19 \%$ above the average. Also, most of high-school adolescents was within the average (48\%), whereas the $30 \%$ performed above and the $22 \%$ below the average, respectively. Between-group comparisons showed that 6MWT performance was significantly lower in primary- compared to middle- $(607.9 \pm 65.0$ vs. $686.7 \pm 71.4$ $\mathrm{m} ; p=.020)$ and high-school (706.4 $\pm 86.6 \mathrm{~m} ; p=.002)$ students (Figure $2 \mathrm{~B}$ ).

The average V'E during 6MWT was $27.1 \pm 8.6,41.8 \pm 12.8$ and $45.7 \pm 16.0 \mathrm{~L} \cdot \mathrm{min}^{-1}$ in primary-, middle- and high-school children, respectively. Significantly higher values were observed in middle- $(p=.011)$ and highschool $(p<.001)$ compared to primary-school children. The average V'E values measured indicate an overall moderate intensity achieved during the 6MWT across the three groups. Post-test RPE was $3.9 \pm 2.5,4.2 \pm$ 1.9 and $4.0 \pm 2.4$ in primary-, middle- and high-school children, respectively. No between-group differences were found for post-test RPE ( $p>.05$ in all cases). These values indicate that similarly to what observed in their parents, children's perceived intensity of the 6MWT was moderate.
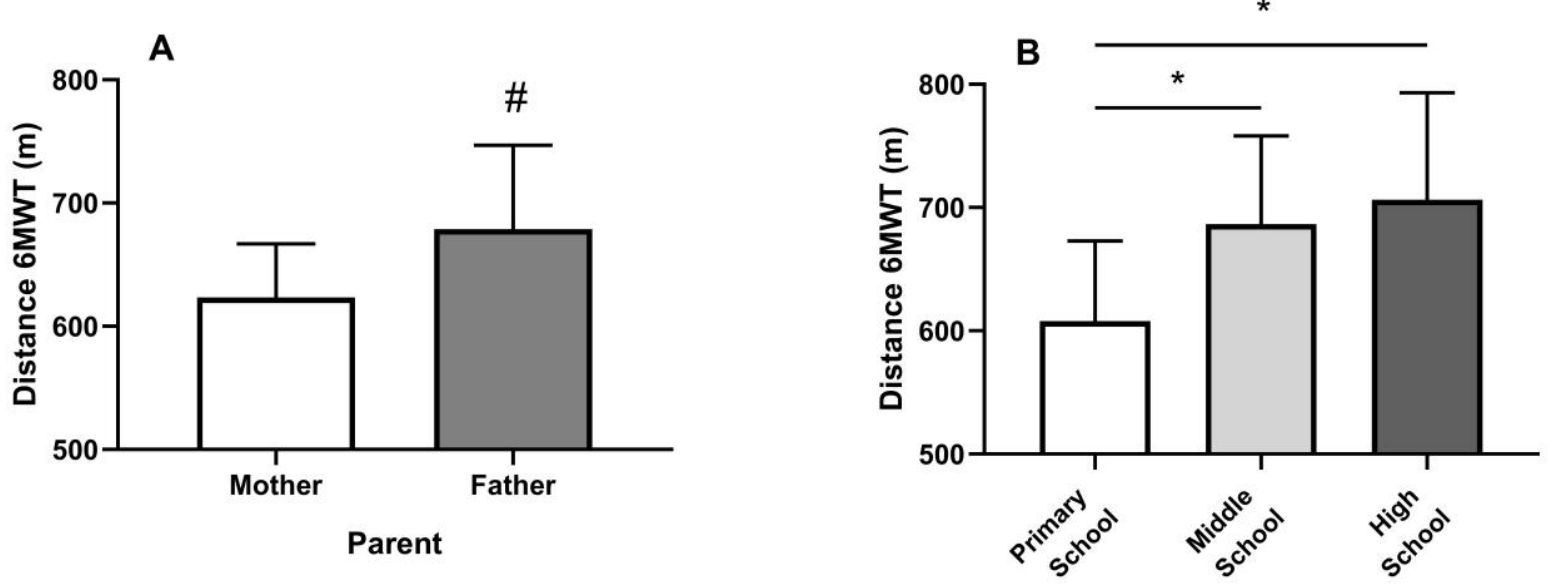

Figure 2. A. Bar plots representing the average distance covered in the 6MWT (m) for mothers (white bars) and fathers (grey bars). B. Bar plots representing the average distance covered in the 6MWT $(\mathrm{m})$ for primary(white bars), middle- (light grey bars) and high-school (dark grey bars) children. Between-group differences are indicated with * if $p<.05$ or with \# if $p<.001$.

\section{Parental influence on children's CMRF and CRF}

When considering all children involved, the regression analyses revealed a positive association between parental and children WC and WHtR, with parental values which explained the $28 \%$ and $18 \%$ of the children's variance, respectively. When the analyses were split by school level, parental WC and WHtR significantly influenced WC and WHtR of primary-school children only, explaining the $60 \%$ and $74 \%$ of their variance, respectively. The subsequent backward stepwise regression model showed that only a maternal WC and WHtR association with their offspring was maintained, explaining alone the $55 \%$ and $68 \%$ of the variance, respectively. Each 1 point increment in WHtR value of the mother was associated with a 0.76 increase in 
their children's value. Moreover, we observed that parental WC and WHtR did not predict children's values in both middle- and high-school students (Table 2).

Table 2. Backward stepwise regression coefficients for CMRF and CRF. Dependent variables were children's $\mathrm{WC}(\mathrm{m}), \mathrm{WHtR}$ and 6MWT $(\mathrm{m})$ performed distance. Independent variables were parental $\mathrm{WC}(\mathrm{m}), \mathrm{WHtR}$ and 6MWT $(\mathrm{m})$ performed distance. Statistically significant regressions are shown in bold.

\begin{tabular}{|c|c|c|c|c|}
\hline Dependent variable & Independent variables & $\beta$ & $\mathbf{R}^{2}$ & $p$ \\
\hline \multirow{2}{*}{$\begin{array}{l}\text { Children } \\
\text { CMRF }\end{array}$} & Parents & & & \\
\hline & $M$ and $F$ & & 0.280 & .0052 \\
\hline \multirow[t]{4}{*}{ WC } & $M$ and $F$ PS & & 0.604 & .0154 \\
\hline & M PS & 0.709 & 0.547 & .0059 \\
\hline & $M$ and $F$ MS & & & .9138 \\
\hline & $M$ and $F$ HS & & & .2438 \\
\hline \multirow[t]{5}{*}{ WHtR } & $M$ and $F$ & & 0.181 & .0412 \\
\hline & $M$ and $F$ PS & & 0.739 & .0024 \\
\hline & MPS & 0.809 & 0.675 & .0011 \\
\hline & $M$ and $F$ MS & & & .8795 \\
\hline & $M$ and $F$ HS & & & .0912 \\
\hline \multicolumn{5}{|l|}{$C R F$} \\
\hline \multirow[t]{5}{*}{ 6MWT } & $M$ and $F$ & & & .8792 \\
\hline & $M$ and $F$ PS & & & .9727 \\
\hline & $M$ and $F$ MS & & & .6139 \\
\hline & $M$ and $F$ HS & & & .0689 \\
\hline & $F H S$ & 0.935 & 0.262 & .0738 \\
\hline
\end{tabular}

CMRF, cardiometabolic risk factors; CRF, cardiorespiratory fitness; WC, waist circumference; WHtR, waist-to-height ratio; $6 M W T$, six-minute walking test; $M$, mother; F, father; PS, primary-school; MS, middle-school; HS, high-school.

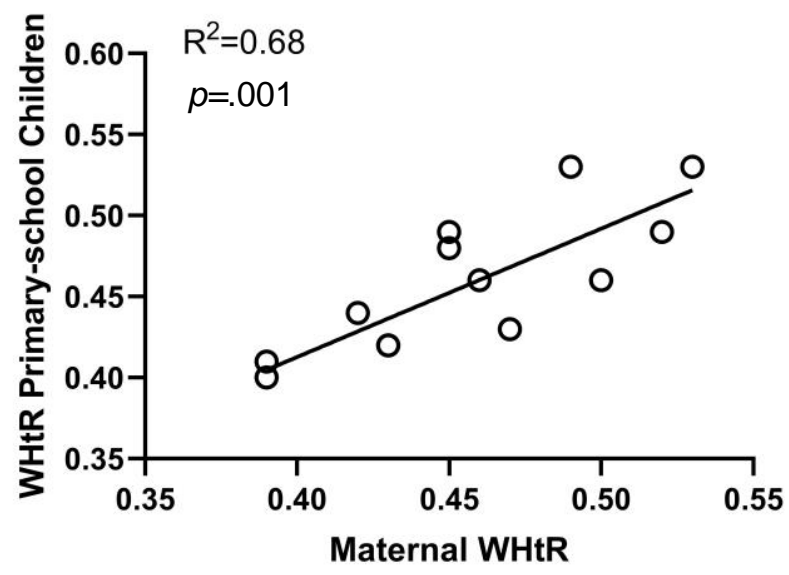

Figure 3. Stepwise regression analysis between parental and children's WHtR. Primary-school children's WHtR regression line plotted as a function of maternal WHtR. The coefficient of determination $\left(R^{2}\right)$ of the linear regression with the relative significance level is reported in the upper left corner of the figure. 
When considering all children involved, parental 6MWT distance was not associated with children's and adolescents' performance. Similarly, when the analyses were split by school level, no significant associations were observed. However, we believe it is worth noting a tendency towards significance between parental 6MWT, and particularly paternal performance, and high-school students' 6MWT performance (Table 2).

\section{DISCUSSION}

The aim of this study was to investigate parental influence on CMRF and CRF levels of school-aged children (6-19 yr.). Furthermore, we aimed at assessing if parental influence may differ across the different stages of education (i.e., primary- vs. middle- vs high-school), as well as if there is a potential differential role played by mothers and fathers. We observed a positive association between parental and children's CMRF. In particular, maternal WC and WHtR were strongly associated with those of their primary-school children. Conversely, no significant association was found between parental and children's CRF, although a tendency towards significance emerged between paternal and high-school children's CRF, which was objectively evaluated in both populations with the 6MWT.

Overall, the participants involved in this study can be considered as representative of a healthy and physically-fit population. Indeed, if compared to the current age and gender-specific normative values for both populations, we observed that: 1) more than half of parents were normal weight (63\%) according to BMl reference cut-off values (World Health Organization, 2000), were at "low-risk" for health (64\%), based on WC reference cut-off values (Bray, 2004), and were classified as "ok" (47\%) or "take care" (5\%) according to WHtR reference cut-off values (Ashwell, 2009); 2) more than half of children were normal weight (71\%), according to BMI reference cut-off values (Cole, 2000; Cole et al., 2007), and were classified as "ok" according to WHtR reference cut-off values (Ashwell, 2009); 3) both populations showed a 6MWT performance within the average (61\%) when compared to reference values (Chetta et al., 2006; Geiger et al., 2007).

Between-group comparisons pointed out that mothers had a lower BMI and WC compared to fathers. Furthermore, BMI and WC were significantly higher in older children compared to the younger ones, which is explained by the physiological growth and development of children across the three levels of schooleducation. Conversely, no differences were observed for WHtR between mothers and fathers and among the three different school levels. The 6MWT performance was significantly affected by both parental gender and children's age.

When considering all parents and children, multiple regression analyses revealed a positive association between parental WC and that of their offspring. This finding suggests that children's WC, a more specific indicator of abdominal fatness than BMI, may be influenced by that of their parents. This adds to the existing evidence that, in addition to parental BMI (Farajian et al., 2014; Magnússon et al., 2008), children's abdominal fatness can also be predicted by parental WC. In particular, when considering the different school levels, a strong parental influence was observed only for primary-school children. This last outcome may extend the conclusion of previous findings, namely that parental fatness would impact that of their older children (11-12 yr.) (Lee et al., 2019). Furthermore, when parental role was taken into consideration, maternal WC showed a stronger positive association with primary-school children's WC, compared to the fathers. These results may suggest that the prevention and control of childhood obesity should start already during developmental years and should focus on the concomitant and multidimensional change and promotion of health behaviours in both parents and children. 
To the best of the authors' knowledge, this is the first study that observed an association between parental and children's WHtR. Consistently to what observed for WC, a strong parental influence was observed only for primary-school children and particularly with respect to maternal values. In addition, the WHtR value of children increased by approximately 0.76 point for each 1 point increment in mothers' value. Moreover, a higher predictability of parental WHtR over BMI and WC of children's CMRF, which was only evident at primary-school level, was also observed.

Parental CRF was not significantly associated with that of their offspring. However, we believe it is worth reporting a tendency towards significance between parental and high-school adolescent's CRF, which was more pronounced for fathers with respect to the mothers. In past literature there was only little and indirect evidence, which sought to demonstrate an association between parental and children's CRF. Indeed, Cleland et al. (2005) observed a positive association between parental PA levels and children's CRF. Similarly, Magnússon et al. (2008) reported a stronger association between fathers' PA levels and children's fitness compared to mothers. However, none of these previous studies tested the association between parental and children's CRF through the adoption of objective measurements in both populations. For this reason, here we adopted, for the first time, the same field test (i.e. 6MWT) to objectively assess CRF in both populations. In light of our preliminary findings, further research is needed to better quantify the influence of parental CRF on that of their offspring.

This study presents some strengths and weaknesses that need to be highlighted. The assessment of both CMRF and CRF was conducted on the whole family unit. Thus, parents and their offspring were evaluated with the same objective tests, which allowed a reliable assessment of the parental-children associations. However, the current research was limited in several ways. Firstly, participants' CMRF and CRF were not directly assessed, but were only estimated through indirect field test (i.e. WC, WHtR, 6MWT). Our methodological choice was justified by the fact that the number of participants and the environmental school context would have made a more direct assessment less feasible. Secondly, the reduced sample size precluded a more detailed gender-specific quantification of parental and children's associations. Thirdly, the adopted study design (e.g. cross-sectional) did not allow the longitudinal monitoring of potential changes of the magnitude of parental-offspring associations across school-educational levels, at the individual subject level.

\section{CONCLUSIONS}

This research has investigated the parental influence on CMRF and CRF of school-aged children (6-19 yr.). The results of this cross-sectional study suggest that parental CMRF may influence those of their offspring. Primary-school children (6-11 yr.) whose mothers had high CMRF were more likely to present high CMRF. Conversely, parental CRF does not seem to influence children's CRF, despite paternal CRF may potentially be associated to high-school adolescent's CRF. In light of our findings, we underline the importance of designing strategies of promotion of healthy behaviours, which should not only involve children but also their families. Further research is warranted to strengthen these preliminary results.

\section{FUNDING STATEMENT}

The Università Cattolica del Sacro Cuore contributed to the funding of this research project and to its publication. The funding body had no role in designing the study, data collection, analysis, interpretation and writing of the manuscript. 


\section{CONFLICT OF INTEREST}

The authors declare that they have no competing interests. Moreover, the authors declare that the results of the study are presented clearly, honestly and without fabrication, falsification or inappropriate data manipulation.

\section{ACKNOWLEDGEMENTS}

The authors extend their sincere gratitude to all the children, their parents, the teachers and school principals for their commitment to the study. Moreover, they wish to thank Cattorini Daniele, Manzella Alberto, Pastori Luca, undergraduate students in Sports and Physical Education at the Università Cattolica del Sacro Cuore of Milan, for their valuable contribution to the data collection.

\section{REFERENCES}

American Thoracic Society, 2002. ATS Statement: Guidelines for the Six-Minute Walk Test. Am. J. Respir. Crit. Care Med. 166, 111-117. https://doi.org/10.1164/ajrccm.166.1.at1102

Anderssen, S.A., Cooper, A.R., Riddoch, C., Sardinha, L.B., Harro, M., Brage, S., Andersen, L.B., 2007. Low cardiorespiratory fitness is a strong predictor for clustering of cardiovascular disease risk factors in children independent of country, age and sex. Eur. J. Cardiovasc. Prev. Rehabil. 14, 526-531. https://doi.org/10.1097/HJR.0b013e328011efc1

Ashwell, M., 2009. Obesity risk: importance of the waist-to-height ratio. Nurs. Stand. 23, 49-54. https://doi.org/10.7748/ns2009.06.23.41.49.c7050

Ashwell, M., Gunn, P., Gibson, S., 2012. Waist-to-height ratio is a better screening tool than waist circumference and BMI for adult cardiometabolic risk factors: systematic review and meta-analysis. Obes. Rev. 13, 275-286. https://doi.org/10.1111/j.1467-789X.2011.00952.x

Borg, G.A.V., 1982. Psychophysical bases of perceived exertion. Med. Sci. Sports Exerc. 14, 377-381. https://doi.org/10.1249/00005768-198205000-00012

Börnhorst, C., Russo, P., Veidebaum, T., Tornaritis, M., Molnár, D., Lissner, L., Mårild, S., De Henauw, S., Moreno, L.A., Floegel, A., Ahrens, W., Wolters, M., 2020. The role of lifestyle and non-modifiable risk factors in the development of metabolic disturbances from childhood to adolescence. Int. J. Obes. https://doi.org/10.1038/s41366-020-00671-8

Bray, G.A., 2004. Don't throw the baby out with the bath water. Am. J. Clin. Nutr. 79, 347-349. https://doi.org/10.1093/ajcn/79.3.347

Casolo, A., Sagelv, E.H., Bianco, M., Casolo, F., Galvani, C., 2019. Effects of a structured recess intervention on physical activity levels, cardiorespiratory fitness, and anthropometric characteristics in primary school children. J. Phys. Educ. Sport 19, 1796-1805. https://doi.org/10.7752/jpes.2019.s5264

Chetta, A., Zanini, A., Pisi, G., Aiello, M., Tzani, P., Neri, M., Olivieri, D., 2006. Reference values for the 6-min walk test in healthy subjects 20-50 years old. Respir. Med. 100, 1573-1578. https://doi.org/10.1016/j.rmed.2006.01.001

Christofaro, D.G.D., Andersen, L.B., Andrade, S.M. de, Barros, M.V.G. de, Saraiva, B.T.C., Fernandes, R.A., Ritti-Dias, R.M., 2018. Adolescents' physical activity is associated with previous and current physical activity practice by their parents. J. Pediatr. (Versão em Port. 94, 48-55. https://doi.org/10.1016/j.jpedp.2017.08.003

Cleland, V., Venn, A., Fryer, J., Dwyer, T., Blizzard, L., 2005. Parental exercise is associated with Australian children's extracurricular sports participation and cardiorespiratory fitness: A cross- 
sectional study. Int. J. Behav. Nutr. Phys. Act. 2, 1-9. https://doi.org/https://doi.org/10.1186/14795868-2-3

Cole, T.J., 2000. Establishing a standard definition for child overweight and obesity worldwide: international survey. BMJ 320, 1240-1240. https://doi.org/10.1136/bmi.320.7244.1240

Cole, T.J., Flegal, K.M., Nicholls, D., Jackson, A.A., 2007. Body mass index cut offs to define thinness in children and adolescents: international survey. BMJ 335, 194. https://doi.org/10.1136/bmi.39238.399444.55

Farajian, P., Panagiotakos, D.B., Risvas, G., Malisova, O., Zampelas, A., 2014. Hierarchical analysis of dietary, lifestyle and family environment risk factors for childhood obesity: the GRECO study. Eur. J. Clin. Nutr. 68, 1107-1112. https://doi.org/10.1038/ejcn.2014.89

Farrell, S.W., Braun, L., Barlow, C.E., Cheng, Y.J., Blair, S.N., 2002. The Relation of Body Mass Index, Cardiorespiratory Fitness, and All-Cause Mortality in Women. Obes. Res. 10, 417-423. https://doi.org/10.1038/oby.2002.58

Farrell, S.W., Finley, C.E., Radford, N.B., Haskell, W.L., 2013. Cardiorespiratory Fitness, Body Mass Index, and Heart Failure Mortality in Men. Circ. Hear. Fail. 6, 898-905. https://doi.org/10.1161/CIRCHEARTFAILURE.112.000088

Geiger, R., Strasak, A., Treml, B., Gasser, K., Kleinsasser, A., Fischer, V., Geiger, H., Loeckinger, A., Stein, J.I., 2007. Six-Minute Walk Test in Children and Adolescents. J. Pediatr. 150, 395-399.e2. https://doi.org/10.1016/j.jpeds.2006.12.052

Han, T.S., Hart, C.L., Haig, C., Logue, J., Upton, M.N., Watt, G.C.M., Lean, M.E.J., 2015. Contributions of maternal and paternal adiposity and smoking to adult offspring adiposity and cardiovascular risk: the Midspan Family Study. BMJ Open 5, e007682. https://doi.org/10.1136/bmjopen-2015-007682

Jago, R., Baranowski, T., Watson, K., Baranowski, J.C., Nicklas, T., Zakeri, I.F., 2004. Relationships Between Maternal and Child Cardiovascular Risk Factors. Arch. Pediatr. Adolesc. Med. 158, 1125. https://doi.org/10.1001/archpedi.158.12.1125

Janssen, I., Katzmarzyk, P.T., Ross, R., Leon, A.S., Skinner, J.S., Rao, D.C., Wilmore, J.H., Rankinen, T., Bouchard, C., 2004. Fitness Alters the Associations of BMI and Waist Circumference with Total and Abdominal Fat. Obes. Res. 12, 525-537. https://doi.org/10.1038/oby.2004.60

Jelastopulu, E., Kallianezos, P., Merekoulias, G., Alexopoulos, E.C., Sapountzi-Krepia, D., 2012. Prevalence and risk factors of excess weight in school children in West Greece. Nurs. Health Sci. 14, 372-380. https://doi.org/10.1111//j.1442-2018.2012.00691.x

Koster, A., Leitzmann, M.F., Schatzkin, A., Mouw, T., Adams, K.F., van Eijk, J.T.M., Hollenbeck, A.R., Harris, T.B., 2008. Waist Circumference and Mortality. Am. J. Epidemiol. 167, 1465-1475. https://doi.org/10.1093/aje/kwn079

Lee, C.Y., Ledoux, T.A., Johnston, C.A., Ayala, G.X., O'Connor, D.P., 2019. Association of parental body mass index (BMI) with child's health behaviors and child's BMI depend on child's age. BMC Obes. 6, 11. https://doi.org/10.1186/s40608-019-0232-x

Lee, S., Kuk, J.L., Katzmarzyk, P.T., Blair, S.N., Church, T.S., Ross, R., 2005. Cardiorespiratory Fitness Attenuates Metabolic Risk Independent of Abdominal Subcutaneous and Visceral Fat in Men. Diabetes Care 28, 895-901. https://doi.org/10.2337/diacare.28.4.895

Li, A.M., 2005. The six-minute walk test in healthy children: reliability and validity. Eur. Respir. J. 25, 1057-1060. https://doi.org/10.1183/09031936.05.00134904

Lo, K., Wong, M., Khalechelvam, P., Tam, W., 2016. Waist-to-height ratio, body mass index and waist circumference for screening paediatric cardio-metabolic risk factors: a meta-analysis. Obes. Rev. 17, 1258-1275. https://doi.org/10.1111/obr.12456 
Magnússon, K.T., Sveinsson, T., Arngrímsson, S.Á., Johannsson, E., 2008. Predictors of fatness and physical fitness in nine-year-old Icelandic school children. Int. J. Pediatr. Obes. 3, 217-225. https://doi.org/10.1080/17477160802169482

McCarthy, H., Jarrett, K., Crawley, H., 2001a. The development of waist circumference percentiles in British children aged 5.0-16.9 y. Eur. J. Clin. Nutr. 55, 902-907. https://doi.org/10.1038/sj.ejcn.1601240

McCarthy, S. N., Harrington, K. E., Kiely, M., Flynn, A., Robson, P. J., Livingstone, M. B., Gibney, M. J., $2001 \mathrm{~b}$. Analyses of the anthropometric data from the North/South Ireland Food Consumption Survey. Public Health Nutr. 4(5A), 1099-1106. https://doi.org/10.1079/phn2001191

Ortega, F.B., Tresaco, B., Ruiz, J.R., Moreno, L.A., Martin-Matillas, M., Mesa, J.L., Warnberg, J., Bueno, M., Tercedor, P., Gutiérrez, Á., Castillo, M.J., 2007. Cardiorespiratory Fitness and Sedentary Activities Are Associated with Adiposity in Adolescents*. Obesity 15, 1589-1599. https://doi.org/10.1038/oby.2007.188

Parrett, A.L., Valentine, R.J., Arngrímsson, S.Á., Castelli, D.M., Evans, E.M., 2011. Adiposity and aerobic fitness are associated with metabolic disease risk in children. Appl. Physiol. Nutr. Metab. 36, 72-79. https://doi.org/10.1139/H10-083

Qin, Y.-Y., Steier, J., Jolley, C., Moxham, J., Zhong, N.-S., Luo, Y.-M., 2010. Efficiency of Neural Drive During Exercise in Patients With COPD and Healthy Subjects. Chest 138, 1309-1315. https://doi.org/10.1378/chest.09-2824

Schoeppe, S., Röbl, M., Liersch, S., Krauth, C., Walter, U., 2016. Mothers and Fathers Both Matter: The Positive Influence of Parental Physical Activity Modeling on Children's Leisure-Time Physical Activity. Pediatr. Exerc. Sci. 28, 466-472. https://doi.org/10.1123/pes.2015-0236

Unnithan, V.B., Murray, L.A., Timmons, J.A., Buchanan, D., Paton, J.Y., 1995. Reproducibility of cardiorespiratory measurements during submaximal and maximal running in children. Br. J. Sports Med. 29, 66-71. https://doi.org/10.1136/bjsm.29.1.66

Vandoni, M., Correale, L., Puci, M.V., Galvani, C., Codella, R., Togni, F., La Torre, A., Casolo, F., Passi, A., Orizio, C., Montomoli, C., 2018. Six minute walk distance and reference values in healthy Italian children: A cross-sectional study. PLoS One 13, e0205792. https://doi.org/10.1371/journal.pone.0205792

Wang, Y., Lobstein, T., 2006. Worldwide trends in childhood overweight and obesity. Int. J. Pediatr. Obes. 1, 11-25. https://doi.org/10.1080/17477160600586747

World Health Organization, 2000. The Asia-Pacific perspective: redefining obesity and its treatment. 